Revista Brasil. Bot., V.31, n.2, p.209-214, abr.-jun. 2008

\title{
Viabilidade polínica de Carica papaya L.: uma comparação metodológica
}

\author{
MÁRCIA MUNHOZ ${ }^{1,5}$, CYNTHIA FERNANDES PINTO DA LUZ², PAULO ERNESTO \\ MEISSNER FILHO ${ }^{3}$, ORTHUD MONIKA BARTH ${ }^{4}$ e FERNANDA REINERT ${ }^{1}$
}

(recebido: 17 de dezembro de 2006; aceito: 27 de março de 2008)

\begin{abstract}
Pollen viability of Carica papaya L.: a methodological comparison). Pollen viability of Carica papaya L. 'Sunrise Solo' cultivar was estimated using in vitro germination and pollen stain tests. Two culture media described in the literature as efficient for pollen in vitro germination of C. papaya were used. Germination was higher in the media without essential elements but with a higher concentration of agar (65\% compared with 51.5\%). These results were compared with viability estimates based on staining pollen. The five stains used to test for pollen viability were: 2,3,5-triphenyl tetrazolium chloride - TTC, Alexander's stain, acetocarmine, iodine-potassium iodide and Sudan IV. Pollen viability estimated with TTC was $67.5 \%$ and similar to germination results providing a reliable estimate of in vitro germination. The four other stains overestimated pollen viability (>90\%), and their use should be restricted to determining cell constituents, and pollen grain integrity.
\end{abstract}

Key words - Carica papaya, in vitro germination, pollen staining, pollen viability

RESUMO - (Viabilidade polínica de Carica papaya L.: uma comparação metodológica). A viabilidade polínica do mamoeiro cultivar 'Sunrise Solo' (Carica papaya L.) foi estudada utilizando germinação in vitro e testes colorimétricos, assim como a validade dos testes colorimétricos como estimativa de viabilidade comparada àquela do teste germinativo. Os dois meios de cultura, descritos na literatura como meios eficientes para germinação da espécie, diferem basicamente pela presença de nutrientes essenciais e concentração de ágar. O meio de cultura sem elementos essenciais e com maior concentração de ágar forneceu o melhor índice de germinação polínica (65\%). Os cinco corantes testados foram: 2,3,5-cloreto de trifeniltetrazólio (TTC), Alexander, carmim acético, lugol e Sudan IV. O teste de coloração com TTC forneceu estimativa de viabilidade $(67,5 \%)$ equivalente ao teste de germinação in vitro e, portanto, confiável de viabilidade polínica. Os demais corantes testados superestimaram a viabilidade polínica $(>90 \%)$, porém são eficientes na determinação de constituintes celulares e da integridade do grão de pólen.

Palavras-chave - Carica papaya, corantes polínicos, germinação in vitro, viabilidade polínica

\section{Introdução}

Estimativas da viabilidade polínica constituem um importante parâmetro em análises de fluxo gênico e em programas de melhoramento genético de plantas (Martins et al. 1981, Botto 1997), especialmente, quando se utilizam técnicas de polinização artificial para hibridação de espécies (Sahar \& Spiegel-Roy 1984, Bolat \& Pirlak 1999, Rodriguez-Riano \& Dafni 2000). Um importante exemplo é o mamoeiro (Carica papaya L.), que vem sendo submetido a programas de melhoramento tradicional e moderno com a finalidade de obterem-se

1. Universidade Federal do Rio de Janeiro, Instituto de Biologia, Centro de Ciências da Saúde, Ilha do Fundão, 21949-900 Rio de Janeiro, RJ, Brasil.

2. Instituto de Botânica, Seção de Dicotiledôneas, Caixa Postal 3005, 01061-970 São Paulo, SP, Brasil.

3. Empresa Brasileira de Pesquisa Agropecuária, Embrapa Mandioca e Fruticultura Tropical, Rua Embrapa, s/nº, 44380-000 Cruz das Almas, BA, Brasil.

4. Instituto Oswaldo Cruz, Fiocruz, Avenida Brasil 4365, 21040-900 Rio de Janeiro, RJ, Brasil.

5. Autor para correspondência:munhoz.m@gmail.com variedades resistentes ao vírus da mancha-anelar (Vegas et al. 2003). As plantas infectadas por este vírus apresentam porte menor, diminuição da taxa de fotossíntese e as perdas da produção podem chegar a $100 \%$ (Mendes et al. 1986). O controle desse vírus é realizado com emprego de agrotóxicos de maneira pouco criteriosa e, além dos problemas ambientais e para saúde, tem sido verificado que certos agrotóxicos reduzem a germinação como também o crescimento do tubo polínico em diversas culturas (Gentile \& Gallagher 1972, Soundarajan 1984, Philomena \& David 1985). O conhecimento da viabilidade polínica de Carica papaya 'Sunrise Solo' em clima tropical, pode fornecer dados valiosos e inéditos para programas de melhoramento vegetal.

Uma vez determinado o momento da maturidade do grão de pólen, sua viabilidade é estimada através de métodos colorimétricos ou germinativos (Dafni 1992, Kearns \& Inouye 1993, Mulugeta et al. 1994, Souza et al. 2002). Entretanto, de acordo com alguns autores, a maioria dos métodos colorimétricos não é adequada para estimar viabilidade polínica (King 1960, Heslop-Harrison \& Heslop-Harrison 1970, Rodriguez-Riano \& Dafni 2000). 
A germinação in vitro utiliza meios de cultura para determinar a capacidade de os grãos de pólen desenvolverem o tubo polínico (Stanley \& Linskens 1974). O sucesso da germinação in vitro depende de vários fatores como temperatura, período de incubação e presença de micro e macronutrientes no meio de cultura (Taylor \& Hepler 1997), além de ajustes da composição dos meios de cultura para cada espécie (Dafni 1992, Stanley \& Linskens 1974, Brewbaker \& Kwach 1963). O teste colorimétrico com 2,3,5-cloreto de trifeniltetrazólio (TTC) reflete a atividade de enzimas desidrogenases envolvidas na atividade respiratória de tecidos vivos. A atividade enzimática do grão de pólen é associada à sua capacidade de germinação (Derin \& Eti 1999). Quando o TTC reage com o hidrogênio produzido pela respiração celular dá ao pólen uma coloração vermelha (Hoekstra \& Bruinsma 1975).

Testes com outros corantes como lugol e sudan IV são utilizados em alguns estudos como indicativos de viabilidade polínica (Souza et al. 2002, Huang et al. 2004). Entretanto, de acordo com outros autores, esses testes estão associados apenas à detecção de substâncias constituintes dos grãos de pólen, como amido e lipídios, que podem estar presentes tanto em grãos de pólen maduros como nos abortados (King 1960, Beyhaut 1988, Rodriguez-Riano \& Dafni 2000). Corantes, como o carmim acético e a solução de Alexander, são também utilizados como indicativos de viabilidade polínica (Mulugeta et al. 1994, Domingues et al. 1999, Rigamoto \& Tyagi 2002), porém para Báez et al. (2002) e Pline et al. (2002) estes testes refletem somente a integridade de estruturas celulares, como núcleo e membrana plasmática.

O presente trabalho teve dois objetivos: avaliar a viabilidade do pólen de Carica papaya 'Sunrise Solo', fornecendo dados específicos dessa cultivar para subsidiar os estudos de melhoramento genético, e comparar testes germinativos e colorimétricos, usualmente utilizados para avaliação de viabilidade polínica.

\section{Material e métodos}

As plantas de Carica papaya 'Sunrise Solo' com dois anos de idade utilizadas nesse estudo fazem parte de um projeto de melhoramento conduzido no Laboratório de Virologia e Biologia Molecular da Embrapa Mandioca e Fruticultura Tropical, em Cruz das Almas, Bahia (1240’19" S, $39^{\circ} 06^{\prime} 22^{\prime \prime} \mathrm{W}$ e aproximadamente $226 \mathrm{~m}$ de altitude). As plantas encontravam-se em teste de campo, em duas fileiras com espaçamento de $3 \mathrm{~m} \times 2 \mathrm{~m}$ entre plantas, num total de quarenta mamoeiros. Foram sorteadas três plantas, das quais obtivemos três botões florais de cada. De cada botão foram retiradas as dez anteras, que tiveram os grãos de pólen removidos e distribuídos em três lâminas de microscópio para cada teste. As lâminas foram consideradas como unidade experimental para os testes estatísticos $(n=27)$. Os grãos de pólen utilizados foram obtidos de botões florais hermafroditas elongata, próximos ao momento de antese. Os botões foram coletados no período da tarde, em dezembro de 2004 e, imediatamente, transportados em placas de Petri para o laboratório. Foram conduzidos sete experimentos de viabilidade, sendo os testes de germinação em dois meios de cultura e os colorimétricos, com cinco corantes específicos.

Testes germinativos in vitro - Foram utilizados os meios de cultura de Traub \& O'Rork (1936), contendo 1,2\% de ágar e $5 \%$ de sacarose (meio 1), e o de Cohen et al. (1989), contendo $0,8 \%$ de ágar, $5 \%$ de sacarose, $100 \mathrm{mg} \mathrm{L}^{-1}$ de nitrato de cálcio, $100 \mathrm{mg} \mathrm{L}^{-1}$ de nitrato de potássio, $100 \mathrm{mg} \mathrm{L}^{-1}$ de ácido bórico e $50 \mathrm{mg} \mathrm{L}^{-1}$ de sulfato de magnésio (meio 2). A escolha dos parâmetros de temperatura de incubação $\left(25^{\circ} \mathrm{C}\right)$ e do período de incubação (24 horas) também se baseou em dados da literatura (Traub \& O'Rork 1936, Brewbaker \& Kwack 1963, Stanley \& Linskens 1974, Cohen et al.1989).

Os meios de cultura foram autoclavados a $121{ }^{\circ} \mathrm{C}$ por 20 minutos, ajustando-se o $\mathrm{pH}$ para 6,5 e vertidos para placas de Petri estéreis em câmara de fluxo translaminar. Após a solidificação, foram retirados blocos de, aproximadamente, $2 \mathrm{~cm}^{2}$ que foram colocados em lâminas de microscopia. As lâminas foram colocadas em câmara úmida (placa de Petri com papel umedecido) e incubadas em câmara de BOD (Biological Oxigen Demand) por 24 horas a $25 \pm 2{ }^{\circ} \mathrm{C}$.

Testes colorimétricos - Os grãos de pólen foram corados com as soluções 2,3,5-cloreto de trifeniltetrazólio (TTC) (Dafni 1992), carmim acético (Kearns \& Inouye 1993), Sudan IV (Baker \& Baker 1979), lugol (Dafni 1992), e de Alexander (Alexander 1980). O TTC indica a presença das enzimas desidrogenases ativas; o carmim acético indica a integridade cromossômica; a solução com lugol indica a presença de amido; a solução de sudan IV a de lipídios e a solução de Alexander contém fucsina ácida e verde de malaquita que reagem, respectivamente, com o protoplasma e a celulose da parede do pólen. Os grãos de pólen foram observados 10 minutos após a adição dos corantes, com exceção do TTC, onde os grãos foram examinados duas horas após a adição do corante, já que a reação com TTC necessita de um período maior de incubação.

A fim de se obter uma amostragem ao acaso dos grãos de pólen germinados e corados, foi utilizado o método de varredura até se alcançar o número total de 300 grãos de pólen por lâmina, em microscópio fotônico com lente objetiva de 10x (Olympus). Após a contagem, foram feitos cálculos para obtenção da percentagem de germinação e coloração dos grãos de pólen. Considerou-se como grão de pólen germinado aquele cujo comprimento do tubo polínico tivesse, visualmente, ultrapassado o diâmetro do próprio grão de pólen. A medida do comprimento do tubo polínico foi realizada após a contagem dos grãos germinados com auxílio de um tambor micrométrico (OSN 221009), acoplado à ocular (10x) em microscópio fotônico (Olympus). As fotomicrocrafias foram geradas utilizando o mesmo microscópio. 
Os resultados foram submetidos à análise de variância e comparados pelo teste de média de Tukey a $P<0,05$. Todos os testes estatísticos foram realizados no programa computacional SAS System para Windows, versão 6.12.

\section{Resultados}

O comprimento médio dos tubos polínicos após 24 horas de incubação nos dois meios de cultura foi significativamente diferente $(1006,4 \mu \mathrm{m}$ no meio $1 \mathrm{e}$ $870,5 \mu \mathrm{m}$ no meio 2) (figuras 1,2 ). Observamos que em períodos maiores de incubação os tubos polínicos se emaranhavam e dificultavam as medições (figura 3).

Os dados de germinação e coloração estão compilados na tabela 1. A germinação polínica de Carica papaya foi significativamente diferente entre os dois meios de cultura. No meio de cultura contendo 5\% de sacarose e $1,2 \%$ de ágar (meio 1), a germinação dos grãos foi de $65 \%$ e no meio de cultura contendo $5 \%$ de sacarose, $0,8 \%$ de ágar e nutrientes (meio 2 ) foi de $51,5 \%$.

O teste com o corante TTC (2,3,5-cloreto de trifeniltetrazólio) indicou a presença de enzimas
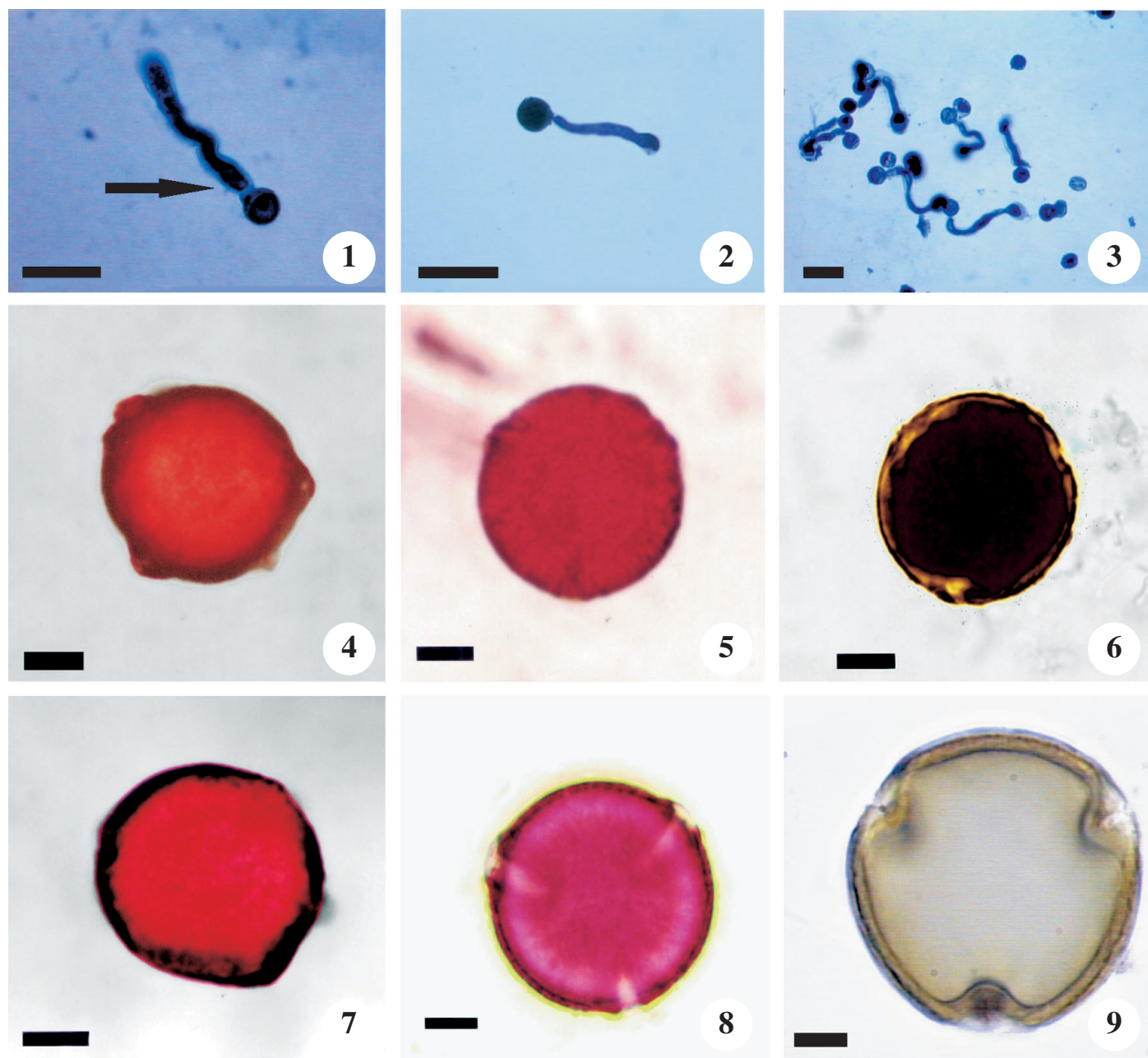

5

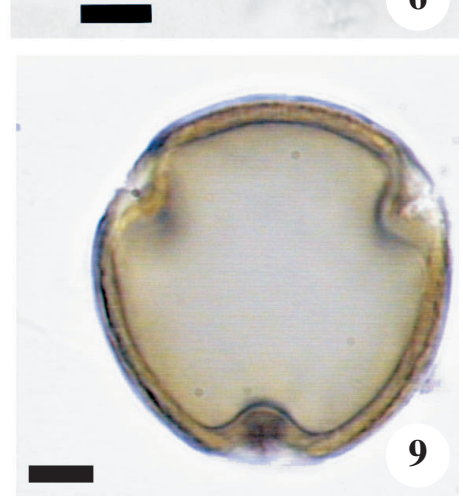

Figuras 1-9. Fotomicrografias de grãos de pólen de Carica papaya. 1-3. Grãos germinados in vitro em dois meios de cultura com 24 horas de incubação, evidenciando-se a variação de tamanho dos tubos polínicos. 1. Meio 1. 2. Meio 2. 3. Vista geral dos grãos de pólen germinados in vitro com 30 horas de incubação, evidenciando o emaranhado de tubos polínicos. As setas indicam os tubos polínicos germinados através de um dos colpos. 4-8. Testes colorimétricos 4. TTC. 5. Carmim acético. 6. Lugol. 7. Sudan IV. 8. Alexander. Barra $=20 \mu \mathrm{m}$ (1-2), $50 \mu \mathrm{m}$ (3), $10 \mu \mathrm{m}$ (4-8), $5 \mu \mathrm{m}$ (9). 9. Grão polínico não corado.

Figure 1-9. Microphotographs of pollen grains of Carica papaya. 1-3. Pollen germinated in vitro in two culture medium, after 24 hours of incubation, showing lenght variation of the pollen tubes. 1. Medium 1. 2. Medium 2. 3. Pollen grains germinated in vitro after 30 hours of incubation, showing curled tubes. Arrows indicate pollen tubes germinated through one of the colpus. 4-8. Stain tests. 4. TTC. 5. Acetic carmin. 6. Iodine-potassium iodide. 7. Sudan IV. 8. Alexander. Bar $=20 \mu \mathrm{m}$ (1-2), $50 \mu \mathrm{m}$ (3), $10 \mu \mathrm{m}$ (4-8), $5 \mu \mathrm{m}$ (9). 9. Unstained pollen grain. 
Tabela 1. Valores médios percentuais e desvio padrão de germinação e coloração dos grãos de pólen de Carica papaya. Grãos de pólen germinados em dois meios de cultura (meio 1: sacarose 5\% e ágar 1,2 \% e meio 2: 0,8\% de ágar, 5\% de sacarose, $100 \mathrm{mg} \mathrm{L}^{-1}$ de nitrato de cálcio, $100 \mathrm{mg} \mathrm{L}^{-1}$ de nitrato de potássio, $100 \mathrm{mg} \mathrm{L}^{-1}$ de ácido bórico e $50 \mathrm{mg} \mathrm{L}^{-1}$ de sulfato de magnésio) e corados com cinco corantes: TTC (2,3,5-cloreto de trifeniltetrazólio), carmim acético, lugol, Sudan IV e Alexander. Letras iguais indicam que não houve diferença significativa entre as médias pelo teste de Tukey a $P<0,05$.

Table 1. Mean percent and standard deviation germination pattern and stained grains of pollen of Carica papaya. Pollen grains germinated in two culture media (medium 1: sucrose 5\% and agar $1.2 \%$ and medium 2: $0.8 \%$ of agar, $5 \%$ of sucrose, $100 \mathrm{mg} \mathrm{L}^{-1}$ of nitrate of calcium, $100 \mathrm{mg} \mathrm{L}^{-1}$ of potassium nitrate, $100 \mathrm{mg} \mathrm{L}^{-1}$ of boric acid and $50 \mathrm{mg} \mathrm{L}^{-1}$ of sulfate of magnesium) and staining with five stains: TTC (2,3,5-triphenyl tetrazolium chloride), acetic carmin, iodine-potassium iodide, Sudan IV and Alexander. Same letters indicate that there was not significant difference among the averages for the test of Tukey $P<0.05$.

\begin{tabular}{|c|c|c|c|}
\hline \multicolumn{2}{|c|}{ Pólen germinado } & \multicolumn{2}{|c|}{ Pólen corado } \\
\hline Meio de cultura & $\%$ de grãos germinados & Corantes & $\%$ de grãos corados \\
\hline meio 1 & $65,0 \pm 6,0^{\mathrm{a}}$ & TTC & $67,5 \pm 2,4^{\mathrm{a}}$ \\
\hline \multirow[t]{4}{*}{ meio 2} & $51,5 \pm 6,3^{b}$ & carmim acético & $92,6 \pm 1,7^{\mathrm{c}}$ \\
\hline & & lugol & $91,2 \pm 1,5^{\mathrm{c}}$ \\
\hline & & sudan IV & $93,3 \pm 2,5^{\mathrm{c}}$ \\
\hline & & Alexander & $98,2 \pm 1,7^{\mathrm{d}}$ \\
\hline
\end{tabular}

desidrogenases ativas em 67,5\% através da coloração vermelha dos grãos de pólen (figura 4). Nos demais testes colorimétricos, obtivemos um alto índice de grãos de pólen corados. Quanto à integridade da cromatina, observamos que 98,2\% dos grãos de pólen foram corados de vermelho intenso com carmim acético (figura 5). $\mathrm{O}$ teste com lugol acusou a presença de amido em mais de 91,2\% dos grãos de pólen, que ficaram corados de marrom (figura 6) e o corante Sudan IV corou de vermelho 93,3\% dos grãos (figura 7), indicando a presença de lipídios. O teste com o corante Alexander sugeriu que 92,6\% dos grãos possuíam protoplama e parede celular íntegras, indicados pela coloração rosa do protoplasma e um fino contorno verde da parede celular (figura 8). Os grãos de pólen não corados apresentam tonalidade acinzentada (figura 9).

\section{Discussão}

O comprimento médio dos tubos polínicos de Carica papaya obtidos no presente estudo foi de três a quatro vezes maior que o obtido por Moreira et al. (2005). Essa diferença pode estar relacionada com o menor tempo de incubação que esses autores utilizaram e com o fato de serem diferentes cultivares de C. papaya.

Alguns autores consideram que o meio de cultura deve incluir, além de carboidratos, elementos estimulantes como ácido bórico, nitrato de cálcio, nitrato de potássio e sulfato de magnésio (Visser 1955, Taylor \& Hepler 1997). Entretanto, o percentual de germinação foi maior no meio 1 , sem elementos essenciais e com $50 \%$ a mais de ágar que o meio 2. Outros autores já relataram resultados semelhantes em ausência de nutrientes (Traub \& O'Rork 1936, Rao \& Lee 1970). Almeida et al. (1986) verificaram a influência da concentração de ágar $(0,8 \%$; $1,0 \% ; 1,2 \% ; 1,5 \%)$ na germinação dos grãos de pólen do algodão (Gossypium hirsutum L.) in vitro, concluindo que o aumento da concentração desse elemento resulta em um melhor desempenho do processo germinativo do pólen. Meios de cultura com um agente solidificante (ágar ou gelatina) têm sido utilizados com sucesso na germinação do pólen de muitas espécies (Visser 1955, Sousa-Lang \& Pinto Junior 1997). Segundo Stanley \& Linskens (1974), o agente solidificante propicia, além da facilidade de incorporação da sacarose ou outros estimulantes de germinação, umidade relativa constante e condições aeróbicas adequadas para uma boa germinação polínica.

Os dois meios de cultura utilizados, como já haviam sido descritos como meios ideais para C. papaya (Traub \& O'Rork 1936, Cohen et al. 1989), foram utilizados como parâmetro para comparação entre os métodos germinativos e os colorimétricos. O teste com TTC foi o único método colorimétrico que forneceu resultados 
semelhantes à estimativa de viabilidade polínica dada pelos testes de germinação in vitro. Diversos autores argumentam que o teste do TTC é uma estimativa confiável da viabilidade polínica, sendo próxima àquela fornecida pelos testes de germinação in vitro (Cohen et al. 1989, Mulugeta et al. 1994, Bolat \& Pirlak 1999, Huang et al. 2004). Além disso, o TTC é muito utilizado por ser um método relativamente rápido e simples, muito embora alguns autores façam ressalvas ao método, afirmando que ele pode fornecer resultados ambíguos, já que grãos de pólen abortados podem fornecer coloração semelhante àquela de grãos viáveis (Heslop-Harrison \& Heslop-Harrison 1970).

Os testes com os quatro outros corantes (Alexander, carmim acético, lugol e sudan IV), embora sejam técnicas muito atrativas pela simplicidade e rapidez, superestimam fortemente a viabilidade polínica quando comparados aos resultados obtidos com TTC e germinação in vitro (King 1960, Heslop-Harrison \& Heslop-Harrison 1970, Stanley \& Linskens 1974, Rodriguez-Riano \& Dafni 2000). De acordo com Alexander (1980), através dos testes com a solução de Alexander, é possível diferenciar os grãos de pólen abortados dos não abortados. Os grãos de pólen abortados não possuem o núcleo e apenas a celulose contida na parede apresentará coloração. Assim, essa solução pode ser considerada como uma ferramenta valiosa para os taxonomistas na identificação de híbridos, por eles não apresentarem núcleo ou apresentarem núcleo alterado.

O presente estudo forneceu dados de viabilidade polínica do cultivar 'Sunrise Solo' de C. papaya e avaliou a validade de testes colorimétricos como estimativa de viabilidade polínica, tendo como referencial, estimativas fornecidas por testes germinativos. Concluímos que os testes com os corantes Alexander, carmim acético, lugol e sudan IV são estimativas ineficientes de viabilidade polínica, embora possam ser usados com eficácia para determinar componentes celulares e a integridade do grão de pólen. Já o TTC mostrou-se uma ferramenta confiável como estimativa rápida de viabilidade polínica.

Agradecimentos - À Coordenação de Aperfeiçoamento de Pessoal de Nível Superior (Capes), pela bolsa concedida à primeira autora durante o mestrado no Programa de Biotecnologia Vegetal da UFRJ; ao Msc. Marcos Leal-Costa, pelo auxílio com as fotomicrografias e a montagem da prancha; aos assessores, pela revisão do manuscrito.

\section{Referências bibliográficas}

ALEXANDER, M.P. 1980. A versatile stain for pollen, fungi, yeast and bacteria. Stain Technology 55:13-18.
ALMEIDA, F.C.G., SILVA, J.F., ALVES, J.F. \& SILVA, P.F. 1986. Estudo da germinação do pólen do algodão, Gossypium hirsutum L., in vitro: I - Efeitos do agar, da sacarose e do cálcio. Ciência Agronômica 17:75-83.

BAÉZ, P., RIVEROS, M. \& LEHNEBACH, C. 2002. Viability and longevity of pollen of Nothofagus species in south Chile. New Zealand Journal of Botany 40:671678.

BAKER, H.G. \& BAKER, I. 1979. Starch in angiosperm pollen grains and its evolutionary significance. American Journal of Botany 66:591-600.

BEYHAUT, R. 1988. Estúdio comparado de dos técnicas para viabilidad de polen en Vitis vinifera. Notas Técnicas, 5. Faculdad de Agronomia, Montevideo .

BOLAT, I. \& PIRLAK, L. 1999. An investigation on pollen viability, germination and tube growth in some stone fruits. Journal of Agriculture and Forestry 23:383-388.

BOTTO, V.O. 1997. Cruzamiento interspecíficos en Eucalyptus sp. In: Actas del XI Congreso Forestal Mundial, Antalya, Turquía 8:1-9. Disponível em http://www.fao.org/ forestry/docrep/wfcxi/publi/v8/es/v8s_e5.htm (acesso em dezembro/2006).

BREWBAKER, J.L. \& KWACK, B.H. 1963. The essential role of calcium ion in pollen germination and pollen tube growth. American Journal of Botany 50:859-865.

COHEN, E., LAVI, U. \& SPIEGEL-ROY, P. 1989. Papaya pollen viability and storage. Scientia Horticulturae 40:317-324.

DAFNI, A. 1992. Pollination ecology: a practical approach University Press, New York.

DERIN, K. \& ETI, S. 1999. Determination of pollen quality, quantity and effect of cross pollination on the fruit set and quality in the pomegranate. Turkish Journal of Agriculture and Forestry 25:169-173.

DOMINGUES, E.T., NETO, A.T. \& SOBRINHO, J.T. 1999. Viabilidade do pólen em variedades de laranja doce. Scientia Agricola 56:265-272.

GENTILE, A.G., GALlAGHER, K.J. 1972. Pollen germination and tube elongation in petunia inhibited or reduced by commercial formulation of pesticides in vitro. Journal of Economic Entomology 65:488-491.

HESLOP-HARRISON, J. \& HESLOP-HARRISON, Y. 1970. Evaluation of pollen viability by enzymatically induced fluorescence; intracellular hydrolysis of fluorescein diacetate. Stain Technology 45:115-120.

HOEKSTRA, F.A. \& BRUINSMA, J. 1975. Respiration and vitality of binucleate and trinucleate pollen. Plant Physiology 34:221-225.

HUANG, Z., ZHU, J., MU, X. \& LIN, J. 2004. Pollen dispersion, pollen viability and pistil receptivity in Leymus chinensis. Annals of Botany 93:295-301.

KEARNS, C.A. \& INOUYE, D.W. 1993. Techniques for pollination biologist. University of Colorado, Niwot.

KING, J.R. 1960. The peroxidase reaction as an indicator of pollen viability. Stain technology 35:225-7. 
MARTINS, M.E., PRERA, L.E.H. \& KAGEYAMA, P.Y. 1981. Manejo de pólen de Pinus para fins de melhoramento genético. Circular Técnica n.18, IPEF, Piracicaba.

MENDES, L.G., DANTAS, J.L.L., MORALES, C.F.G. 1986. Mamão: cultura, matéria-prima, processamento e aspectos econômicos. Série Frutas Tropicais 7, ITAL Campinas.

MOREIRA, D.M., PICANÇO, M.C., SKLWRONSKI, L., COUTO, F.A.A.C., ROSADO, J.F. \& FIDELIS, E.G. 2005. Interferência in vitro de pesticidas e condições ideais para a germinação e crescimento do tubo polínico do mamoeiro (Carica papaya L.). Acta Scientiarum Agronomy 27:171-176.

MULUGETA, D., MAXWELL, B.D., FAY, P.K. \& DYER, W.E. 1994. Kochia (Kochia scoparia) pollen dispersion, viability and germination. Weed Science 42:548-552.

PHILOMENA, P.A., DAVID, B.V. 1985. Effect of pesticides in vitro pollen germination and growth yeld of okra. Current Science 18:927-928.

PLINE, W.A., EDMISTEN K.L., OLIVER, T., WILCUT, J.W., WELLS, R. \& ALLEN, N.S. 2002. Use of digital image analysis, viability stains, and germination assays to estimate conventional and glyphosate-resistant cotton pollen viability. Crop Science 42:2193-2200.

RAO, A.N. \& LEE, Y. K. 1970. Studies on Singapore pollen. Pacific Science 24:255-268.

RIGAMOTO, R.R. \& TYAGI, A.P. 2002. Pollen fertility status in coastal plant species of Rotuma Island. The South Pacific Journal Natural Science 20:30-33.

RODRIGUEZ-RIANO, T. \& DAFNI, A. 2000. A new procedure to asses pollen viability. Sexual Plant Reproduction 12:241-244.
SAHAR, N. \& SPIEGEL-ROY, P. 1984. Citrus pollen storage. Horticultural Science 15:81-2.

SOUNDARAJAN, K. 1984. Effect of certain pesticides on pollen germination in egg plant and okra. Pesticides 18:27.

SOUSA-LANG, V.A. \& PINTO JUNIOR, J.E. 1997. Influência do meio de cultura na germinação do pólen de três espécies de Eucalyptus. Boletim de Pesquisa Florestal 34:45-54.

SOUZA, M.M., PEREIRA, T.N.S. \& MARTINS, E.R. 2002. Microsporogênese e microgametogênese associadas ao tamanho do botão floral e da antera e viabilidade polínica em maracujá-amarelo (Passiflora edulis Sims f. flavicarpa Degener). Ciência e Agrotecnologia. Lavras 26:1209-1217.

STANLEY, R.G. \& LINSKENS, H.F. 1974. Pollen: biology, biochemistry and management. Springer-Verlag, Berlin.

TAYLOR, L.P. \& P.K. HEPLER. 1997. Pollen germination and tube growth. Annual Review of Plant Physiology and Plant Molecular Biology 48:461-91.

TRAUB, H.P. \& O'RORK, C.T. 1936. Papaya pollen germination and storage. Proceeding of the American Society for Horticultural Science 34:18.

VEGAS, A., TRUJILLO, G., SANDREA, Y. \& MATA, J. 2003. Obtención, regeneration y evaluación de híbridos intergenéricos entre Carica papaya y Vasconcellea cauliflora. Interciencia 28:710-714.

VISSER, T. 1955. Germination and storage of pollen. Mededelingen van de Landbouwhogeschooll te Wageningen/Nederland 55:1-68. 